\title{
Strategic considerations in block caving
}

\author{
R.J. Butcher Barrick Gold of Australia Ltd, Australia \\ G. Smith Barrick Gold of Australia Ltd, Australia
}

\begin{abstract}
Over the last 20 years there have been considerable advances in geotechnical techniques used in the design of block caves. However, despite these advances the successful development of a block caving project relies heavily on many non geotechnical factors such as commodity price, exchange rate and development exploration timing. An understanding of the impacts of these factors is important as they can have a material impact on size, depth and method of undercutting a block cave. This paper further discusses the impacts of fluctuations in commodity prices on cave design by the use of a conceptual model, developing guidance in terms of potential mitigation strategies and options to be employed.
\end{abstract}

\section{Introduction}

Over the last twenty years there have been considerable advances in geotechnical techniques used in the design of block caves. However, despite these advances the successful development of a block caving project relies heavily on many non geotechnical factors. This paper describes the influence of non geotechnical factors on a block caving project and how these factors ultimately shape the direction of the geotechnical programme. In this respect key non geotechnical factors which are going to be considered are:

- commodity price

- exchange rate

- exploration development timing

- end of life dilution.

In order to study these factors a conceptual block cave study was undertaken using data from Barrick records. In this respect it should be understood that most of the models' outcomes describe the impact of non geotechnical factors in terms of copper deposits.

\section{Conceptual model description}

The conceptual model considered a vertical copper orebody, with a high grade core of $1.4 \%$ copper reducing to a grade of $0.5 \%$ at the outer extremity. Three different caving block heights were considered; namely 300 , 500 and $700 \mathrm{~m}$. The same undercut and extraction level layouts were utilised for all scenarios, based on that indicated by Butcher and Thin (2007) and Butcher (2003).

Access to the orebody was assumed to be initially via decline for exploration purposes, followed closely by a haulage shaft for production.

The physical characteristics of each scenario are shown in Table 1. 
Table 1 Scenario physical characteristics

\begin{tabular}{lllll}
\hline Parameter & Scenario 1 & Scenario 2 & Scenario 3 & Scenario 4 \\
\hline Ore diameter & $120 \mathrm{~m}$ & $170 \mathrm{~m}$ & $230 \mathrm{~m}$ & $300 \mathrm{~m}$ \\
$\mathrm{HR}$ & 30 & 42.5 & 57.4 & 75 \\
Incremental grade & $1.4 \%$ & $1.1 \%$ & $0.8 \%$ & $0.5 \%$ \\
Average grade & $1.4 \%$ & $1.25 \%$ & $1.05 \%$ & $0.82 \%$ \\
Undercut development metres & 4,006 & 5,409 & 6,707 & 7,652 \\
Extraction development metres & 4,519 & 6,139 & 8,886 & 11,333 \\
Infrastructure development metres & 828 & 828 & 828 & 828 \\
Production rate (Mtpa) & 2.2 & 4.4 & 8.0 & 13.6 \\
\hline
\end{tabular}

\section{Commodity price and exchange rate}

Due to the long life of block caving projects and the long project development times, factors external to geotechnical issues sometimes have a profound impact on the project's nature. In some cases it is necessary that commodity prices are held to their current levels for at least 20 years to ensure viability. In the last 20 years block caving has been used to extract very low grade copper deposits and hence the impacts of commodity price are heightened. Today many block caves are mined with copper grades in the region of $0.4-0.8 \%$ copper. In certain cases, such projects are only viable when copper prices are greater than US $\$ 1.50 / \mathrm{lb}$. Should the copper price fall during the project development or exploration stages, the company owners are faced with three alternatives:

- $\quad$ stop the project

- suspend the project until prices recover

- reconfigure the project to ensure better economic viability.

In the first two cases, if exploration development has not started the geotechnical impacts would be minimal. However, if shafts or adits had been sunk then some form of geotechnical impact would be seen. This geotechnical impact would most notably take the form of:

- securing workings for abandonment

- increasing support levels of workings to prevent time dependant failure during commodity price downfalls

- increasing the corrosion resistance of support elements in shafts and tunnels

- investigating the maintenance of dewatering measures and the impact of excavation flooding on the environment and on a potential future project.

However, in geotechnical terms the most notable impacts of lower commodity prices are in terms of potential project reconfiguration. This project reconfiguration could take three potential forms:

- the block height of the cave is increased to improve returns

- the footprint of the cave is reduced to mine a high grade core

- the footprint is expanded to improve returns

- both the block height and footprint are expanded.

An illustration of how the block geometry can change is given in Figures 1 and 2. Figure 1 shows that as copper prices fall below the US $\$ 2.75 / \mathrm{lb}$ mark, block heights have to be increased substantially. In many cases block heights are doubled and can exceed the limits of current mining experience, in the region of 500 
m (Flores and Karzulovic, 2004). In essence, in geotechnical terms Figure 1 shows that when copper prices fall below US $\$ 2.25 / \mathrm{lb}$, caving becomes geotechnically risky. The main issue with increasing block height is that operational depth increases and the risk of cave stall also can increase as the height to width ratio of the block to be mined increases beyond acceptable norms (i.e. greater than 2 or 3 ).

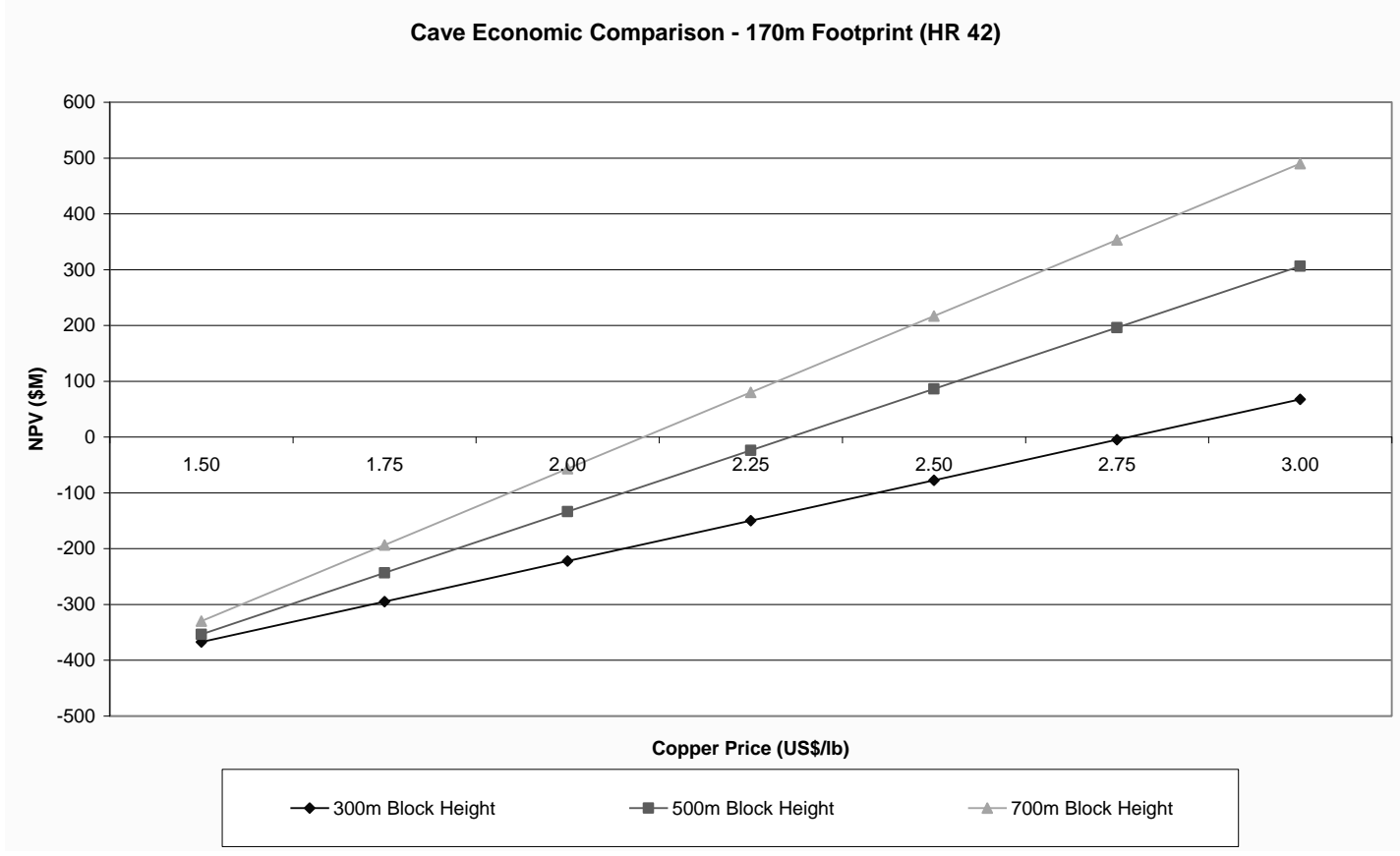

Figure 1 Economic comparison for varying block heights

In discussion of the first point, an increase in operational depth poses certain challenges. The first one of these challenges is that undercutting strategies can change from post-undercutting to advanced, or pre-undercutting for stress protection. This change in undercutting strategy has material impacts in terms of project costs and cave development time. As a general rule, the following applies for development of an undercutting strategy (Butcher, 1999, 2000; Bartlett and Croll, 2000):

- post-undercutting can be successfully used to a depth of $500 \mathrm{~m}$

- advanced-undercutting is viable as a stress protection method from 500-700 m

- $\quad$ stress protection requires pre-undercutting below a depth of $700 \mathrm{~m}$.

The above rules are considered as first pass guidelines to give design engineers an understanding of the impacts of increasing block height to improve viability. However, numerical analysis will be required to confirm the first pass rules. Beck et al. (2006) show a case of a potential cave where a horizontal stress regime changed the current perception of undercutting strategies. In this case Beck et al. (2006) showed that it was not only the depth below surface that had an impact on the undercutting method but the dip and dip direction of the stress field.

Not only does increasing the block height and increasing depth impact the geotechnical design of a block cave, but also there is a risk that rock masses could become weaker or stronger at depth. This risk again leads to challenges in terms of fragmentation, extraction level protection and siting of auxiliary excavations. It also means that geotechnical investigation programmes expand as the need to gain information from greater depth becomes important. The most notable aspect is that the amount of exploration drilling increases.

Figure 2 shows the impact of trying to expand footprint dimensions to improve project viability after cave heights have been increased to their maximum experiential limit of $500 \mathrm{~m}$. Figure 2 shows that as copper prices increase, the lower grade material at the larger footprint scales become viable. 


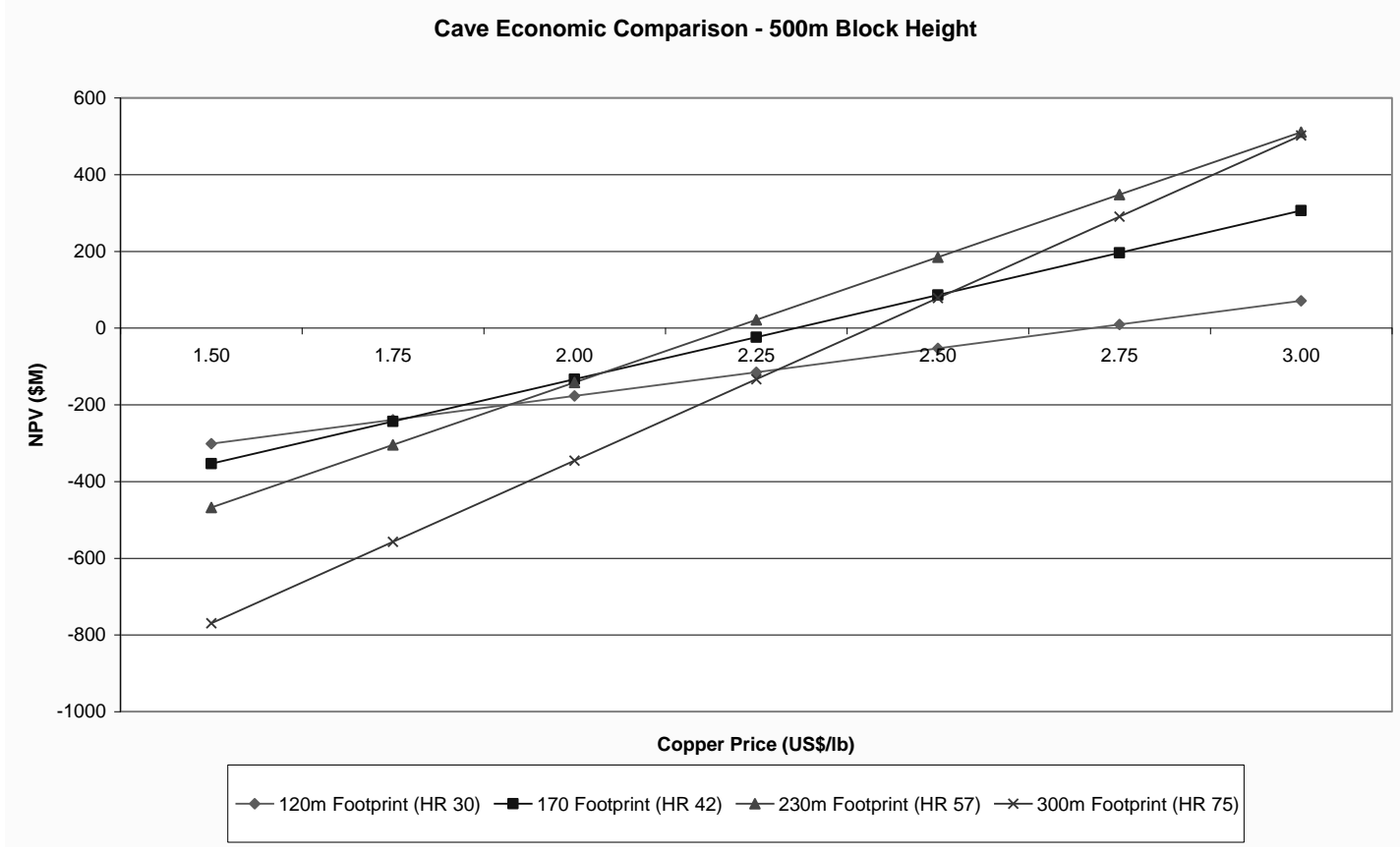

Figure 2 Comparison of varying footprints for $500 \mathrm{~m}$ block height

Footprint expansion as a means of improving the economics of a project again attracts a certain degree of geotechnical risk. One of the main geotechnical risks in such a strategy is that the undercut front will have to be large. Areneda and Sougarret (2007) show that undercut fronts should be kept to a maximum of $300 \mathrm{~m}$ for stress and seismic control. Butcher (2003) suggests that when cave hydraulic radii of greater than 28 have to be mined stress control and cave propagation becomes an issue. In practical terms, Areneda and Sougarret (2007) also show that a further risk of pre-undercutting is the amount of development that has to be excavated in front of the cave. Experience from South America has shown that developing large cave fronts can be challenging and can lead to crushing of the undercut front. Such experiences have also challenged the concept of pre-undercutting as a method of stress control.

As described previously, not only does commodity price have a profound impact on the geometry of a caving project, but foreign exchange rates can also have a material impact. In this regard, the impacts of foreign exchange can be considered to be similar to that of commodity prices for a project reporting in local currency, as revenues will fluctuate inversely to movements in the exchange rate.

\section{$4 \quad$ Exploration development timing}

A major consideration when commodity prices fall is the timing of cave exploration development. At the present time, with large caving projects it is considered necessary that shafts and adits are developed to collect geotechnical data. Whereas most people would tend to agree the necessity of this development, the debate can rage regarding when such development should start. At the present time some geotechnical engineers are advocating that exploration development should commence during the scoping study stage. Since this development can cost upwards of US\$ $100 \mathrm{M}$ in the case of a large caving project, to commit to this expenditure before the project's viability has been confirmed could be seen as a major risk. This debate is heightened during times when commodity prices fall and exploration projects can take many years. The need to gain geotechnical data and have a look at the rock mass are important, but this will entail considerable expenditure without a return if the project proves to be non viable. It should be further understood that exploration development cannot totally give a full understanding of the rock mass as the width of exposure is limited to the width of the tunnel being developed. It therefore has to be challenged if such development is prudent before the project has proved viable. In this respect many companies may well be prepared to undertake this risk if the rewards are large enough and exploration capital is tax deductable. 
However, where a company may be risk adverse, Butcher (2004) gives guidance in terms of criteria that should be adhered to before commencing such exploration development, namely:

- the project concepts have been finalised

- the project risks/potential risks have been determined

- the project appears viable with strong discounted cash flow indicators when related to corporate hurdles

- the resource has been geologically defined to an indicated category

- all existing geotechnical data has been analysed, compiled and the conceptual geotechnical model has been formulated

- the potential impacts of mining stresses are understood

- the aims of the exploration programme are defined

- a geotechnical investigation and risk study have been undertaken for the exploration shaft/decline.

It also may be preferable to investigate if the exploration development can be integrated into the main cave plan to save costs and consider options to conduct limited salvage mining to cover capital costs if the project does not prove viable.

\section{$5 \quad$ End of life dilution}

Pretorius (2007) describes how the ore reserves of the Palabora underground mine were affected by dilution from a large open cut failure. Pretorius describes how the original ore reserve was reduced by $30 \%$. This figure was confirmed by the use of physical models to calibrate cave dilution entry points. Even though geotechnical engineers are mainly concerned with the draw profiles and waste ingress percentages, a further impact that is not normally considered is that of commodity price. In essence, as commodity prices increase, the amount of waste reporting to drawpoints can increase with ore reserves still being economic. Obviously the impacts of cost escalation as well as potential process cost reductions due to reduced milling with fine ore at the end of the block cave have got to be taken into account in this regard. Figure 3 illustrates this impact in terms of a simple shut-off grade calculation. It therefore becomes evident that cave dilution levels should be periodically assessed for viability in terms of commodity price fluctuations.

Cut Off Variation and Dilution Curves

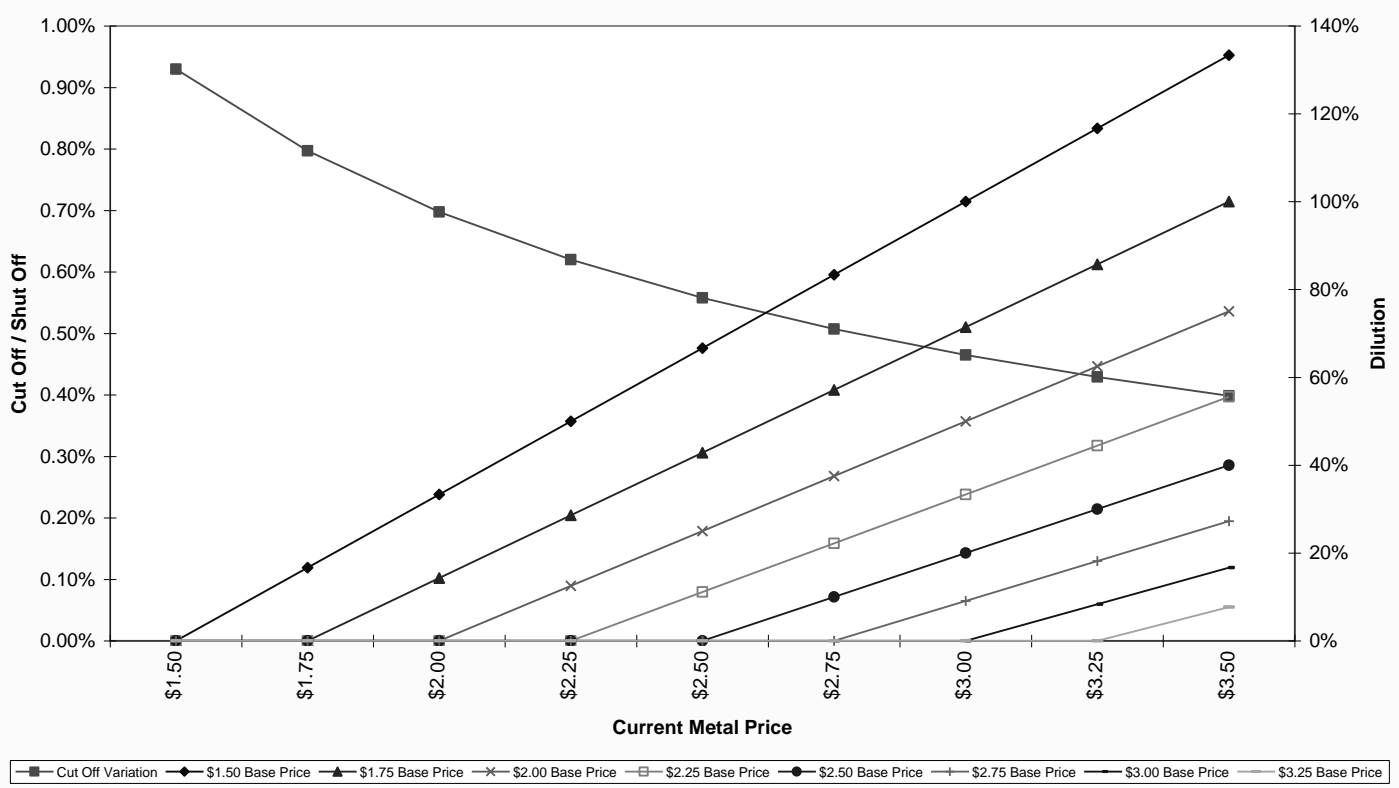

Figure 3 Variation in cutoff grade and dilution curves 


\section{Conclusions}

This paper has illustrated that a number of non geotechnical factors can have a major impact on the geotechnical design of a block cave. In taking cognisance of this it is important at the initial stages of a caving project to understand the potential impacts of such non geotechnical factors. Such factors not only have an effect on cave design stages, but also during the operational phase in terms of dilution assessment. The decision to commit to exploration development is also considered to be at a higher risk during lower commodity prices, but by ensuring that the project is robust both geotechnical and mining viability aims can be achieved.

\section{References}

Areneda, O. and Sougarret, A. (2007) Keynote Address: Lessons learned in cave mining: El Teniente 1997-2007, in Proceedings First International Symposium on Block and Sub-level Caving, Southern African Institute of Mining and Metallurgy, Johannesburg, South Africa, pp. 59-72.

Bartlett, P.J. and Croll, A. (2000) Cave mining at Premier Diamond Mine, in Proceedings MassMin 2000, Australasian Institute of Mining and Metallurgy, Melbourne, Victoria, pp. 227-235.

Beck, D., Arndt, S., Thin, I., Stone, C. and Butcher, R. (2006) A conceptual sequence for a block cave in an extreme stress and deformation environment, in Proceedings Deep and High Stress Mining, Australian Centre for Geomechanics, Perth, Australia, pp. 65-76.

Butcher, R.J. (1999) Design rules for avoiding draw horizon damage in deep level block caves, Southern African Institute of Mining and Metallurgy, Johannesburg, South Africa, Vol. 00, No. 2, pp. 151-155.

Butcher, R.J. (2000) Block cave undercutting - aims, strategies and methods and management, in Proceedings MassMin 2000, Australasian Institute of Mining and Metallurgy, Melbourne, Australia, pp. 113-119.

Butcher, R.J. (2003) Cave Mining Geomechanics, course notes, Australian Centre for Geomechanics, Perth, Australia.

Butcher, R.J. (2004) DEESA - An approach to determine if an orebody will cave, in Proceedings MassMin 2004, Santiago, Chile, pp. 49-54.

Butcher, R.J. and Thin, I.G.T. (2007) The inputs and choices for predicting fragmentation in block cave projects, in Proceedings First International Symposium on Block and Sub-level Caving, Southern African Institute of Mining and Metallurgy, Johannesburg, South Africa, pp. 35-49.

Flores, G. and Karzulovic, A. (2004) Current practices and trends in cave mining, in Proceedings MassMin 2004, Santiago, Chile, pp. 83-90.

Pretorius, D. (2007) The effect of dilution on the underground block cave ore reserves at Palabora Mining Company, in Proceedings First International Symposium on Block and Sub-level Caving, Southern African Institute of Mining and Metallurgy, Johannesburg, South Africa, pp. 73-81. 